\title{
RESEARCH
}

\section{Proton pump inhibitor use and risk of community-acquired Clostridium difficile-associated disease defined by prescription for oral vancomycin therapy}

\author{
Sandra Dial, J.A. Chris Delaney, Verena Schneider, Samy Suissa
}

$\infty \quad$ See related article page 757

\section{ABSTRACT}

Background: The association between the use of proton pump inhibitors and the risk of Clostridium difficile-associated disease (CDAD) is controversial. In this study we re-examined a previously reported association between the use of proton pump inhibitors and the development of community-acquired CDAD, this time using an alternative case definition of the disease.

Methods: We performed a case-control study of community-acquired CDAD using a United Kingdom clinical research database. Patients receiving oral vancomycin therapy were identified as having CDAD, the only indication for this drug. Each case subject was matched with up to 10 control subjects. Neither the cases nor the controls had been admitted to hospital in the year before the date of the vancomycin prescription (index date). Conditional logistic regression analysis was used to adjust for key covariates.

Results: We identified 317 cases of community-acquired CDAD treated with oral vancomycin therapy and $316_{7}$ matched control subjects. Exposure to a proton pump inhibitor in the go days before the index date was associated with an increased risk of CDAD (odds ratio [OR] 3.5, 95\% confidence interval $[\mathrm{Cl}] 2 \cdot 3-5 \cdot 2$ ). Antibiotic exposure in the 90 days before the index date was also a significant risk factor for community-acquired CDAD (OR 8.2, 95\% Cl 6.1-11.0), even though $45 \%$ of the case subjects had not received a prescription for an antibiotic during that period. Certain comorbidities, in particular renal failure, inflammatory bowel disease and malignant disease, as well as prior methicillinresistant Staphylococcus aureus infection, were also associated with an increased risk.

Interpretation: Proton pump inhibitor use was associated with an increased risk of community-acquired CDAD, when cases were defined by receipt of prescription for oral vancomycin therapy. Prior antibiotic exposure was also a significant risk factor, but a significant proportion of the patients with community-acquired CDAD had no such exposure.

CMAJ 2006;175(7):745-8
$\mathrm{R}$ ecent reports have indicated that the use of proton pump inhibitors may increase the risk of severe infections, ${ }^{1-5}$ including Clostridium difficile-associated disease (CDAD). In a recent study using the United Kingdom's General Practice Research Database (GPRD), cases of $\mathrm{CDAD}$ were defined on the basis of a laboratory diagnosis (a positive toxin assay result) or a physician's diagnosis. ${ }^{1} \mathrm{How}-$ ever, a clinical diagnosis without a record of a laboratory confirmation has been criticized. It is possible that patients with a clinical diagnosis of CDAD were positive for the toxin but that their physician had not recorded the laboratory result in the database. Since March 2002 there have been changes in the UK health care system and GPRD in the reporting of $\mathrm{CDAD}$, and laboratory results are now transferred electronically directly into the database. ${ }^{6,7}$ These changes have increased the proportion of cases being diagnosed on the basis of a positive toxin assay result.

We thus re-examined the association between gastric acid suppressive therapy (in particular, proton pump inhibitors) and the risk of CDAD using an alternative outcome definition for CDAD that is less likely to be affected by a recording bias, namely a prescription for oral vancomycin therapy, whose only indication is the treatment of CDAD. ${ }^{8,9}$ This definition also implies that these would be clinically relevant cases of CDAD.

\section{Methods}

We obtained data from the United Kingdom's GPRD. The GPRD is the world's largest and most comprehensive computerized database of anonymous longitudinal medical records from primary care (www.gprd.com) and has been used worldwide for research. Data are collected for over 3 million active patients (about 9 million total) from about 400 primary care practices throughout the United Kingdom. It has been demonstrated that there is good agreement between GPRD data and prescribing data and national data from the Prescription Pricing Authority (based on dispensing). ${ }^{10}$ Primary care practices are required to record a minimum of $95 \%$ of prescriptions and relevant encounters with patients. Data from practices are routinely validated by internal checks. Only data meeting the minimum standards are added to the research database, and practices that fail to meet the required standards 
are removed. ${ }^{11}$ Several validation studies of the GPRD have confirmed the quality and completeness of the data. ${ }^{12,13}$

A case-control approach was used. All patients with a first prescription of oral vancomycin therapy recorded in the database between Jan. I, I994, and Dec. 3I, 2004, were included as the case series. To avoid including patients receiving treatment for relapses, we excluded patients who had either a clinical diagnosis or toxin-positive assay result recorded 30 days to $\mathrm{I}$ year before the prescription date. To define community-acquired $\mathrm{CDAD}$, patients were limited to those who had not been admitted to hospital in the year before their first prescription for oral vancomycin therapy. Using this definition, we observed that there was no overlap between these cases and the cases included in a previous study. ${ }^{1}$ The date of the vancomycin prescription was defined as the index date. For each case, up to Io control subjects were selected from patients attending the same general practice, matched by age ( \pm 2 years), who had not been admitted to hospital in the year before the index date, had not received a prescription for oral vancomycin therapy and were neither toxin positive nor had had a clinical diagnosis of CDAD recorded by the index date. Both cases and controls had to have had at least 2 years of follow-up in the database before the index date.

Patients were classified as currently exposed to a drug of interest (i.e., gastric acid suppressant agent or antibiotic) if they received a prescription for the drug in the 9o-day period before

Table 1: Characteristics of patients with community-acquired Clostridium difficile-associated disease (CDAD)*

\begin{tabular}{|c|c|c|}
\hline \multirow[b]{2}{*}{ Characteristic } & \multicolumn{2}{|c|}{ Group; no. (\%) of patients $†$} \\
\hline & $\begin{array}{c}\text { Cases } \\
n=317\end{array}$ & $\begin{array}{l}\text { Controls } \\
n=3167\end{array}$ \\
\hline Age, yr, mean (SD) & $65.0(19.6)$ & $64.9(19.5)$ \\
\hline Sex, male & $116(36.6)$ & $1315(41.5)$ \\
\hline \multicolumn{3}{|l|}{$\begin{array}{l}\text { Comorbid conditions in } \\
\text { the } 2 \text { yr before index date } \neq\end{array}$} \\
\hline \multicolumn{3}{|l|}{ Gastrointestinal } \\
\hline Inflammatory bowel disease & $18 \quad(5.7)$ & $6 \quad(0.2)$ \\
\hline Diverticular disease & $7 \quad(2.2)$ & $32(1.0)$ \\
\hline Peptic ulcer disease & $1 \quad(0.3)$ & $3 \quad(0.1)$ \\
\hline $\begin{array}{l}\text { Gastroesophageal reflux } \\
\text { disease }\end{array}$ & $13 \quad(4.1)$ & $67 \quad(2.1)$ \\
\hline \multicolumn{3}{|l|}{ Other } \\
\hline Renal failure & $17 \quad(5.3)$ & $22 \quad(0.7)$ \\
\hline Diabetes & $14 \quad(4.4)$ & $139 \quad(4.4)$ \\
\hline MRSA & $5 \quad(1.6)$ & $3 \quad(0.1)$ \\
\hline Cancer (solid tumour) & $5 \quad(1.6)$ & $12(0.4)$ \\
\hline Leukemia or lymphoma & $3 \quad(0.9)$ & $3 \quad(0.1)$ \\
\hline Pernicious anemia & $1 \quad(0.3)$ & $3 \quad(0.1)$ \\
\hline COPD & $21 \quad(6.6)$ & $98 \quad(3.1)$ \\
\hline
\end{tabular}

Note: $\mathrm{SD}=$ standard deviation, MRSA = methicillin-resistant Staphylococcus aureus, $\mathrm{COPD}=$ chronic obstructive pulmonary disease.

*Cases of CDAD are defined by receipt of prescription for oral vancomycin therapy.

†Unless stated otherwise.

$\ddagger$ The index date is the date of prescription for oral vancomycin therapy. the index date. Otherwise they were considered unexposed.

The comorbid conditions that were considered in the previous study ${ }^{1}$ were re-examined in this study and included inflammatory bowel disease, diverticular disease, peptic ulcer disease and gastresophageal reflux disease, Helicobacter pylori-associated disease, pernicious anemia, renal failure (including dialysis), cancer (including solid tumour and hematologic malignant diseases), methicillin-resistant Staphylococcus aureus (MRSA) infection, diabetes mellitus, chronic obstructive pulmonary disease and cirrhosis. The presence of comorbid conditions was assessed in the 2-year period before the index date. We also adjusted for prescriptions of antibiotics, $\mathrm{H}_{2}$-receptor antagonists, NSAIDs and ASA given in the 90 days before the index date.

All analyses were based on conditional logistic regression to estimate the odds ratio (OR) of treated CDAD for the risk factors under study. The adjusted ORs of community-acquired treated CDAD were estimated for current use of proton pump inhibitors, $\mathrm{H}_{2}$-receptor antagonists and antibiotics after adjustment for sex, comorbid conditions and concurrent prescriptions for NSAIDs or ASA. All covariates examined were kept in the final model, since they had been reported to be associated with an increased risk of CDAD in previous studies and could possibly confound the association between use of proton pump inhibitors and antibiotics and CDAD. In these analyses, a $p$ value of less than 0.05 was considered to be significant.

\section{Results}

There were 48I eligible patients who received a prescription for oral vancomycin therapy during the study period. Of these patients, $317(65.9 \%)$ had not been admitted to hospital in the year before and were retained as cases in the study. None of these cases had been coded in the database as being toxin positive at any time, including in the 30 days before the vancomycin prescription date (index date). The 317 patients who received vancomycin had a mean age of 65.0 years and were predominantly female (Table I). After controlling for all covariates shown in Table I, as well as exposure to antibiotics, NSAIDs and ASA, we observed a strong association between treated CDAD and current proton pump inhibitor exposure (OR 3.5, 95\% confidence interval [CI 2.3-5.2). Use of an $\mathrm{H}_{2}$-receptor antagonist was not significantly associated with an increased risk of CDAD (OR I.4, 95\% CI o.8-2.5). Prior antibiotic exposure was the most important of the medication exposures (OR 8.2, 95\% CI 6.I-II.0), even though $45 \%$ of the cases were not exposed to antibiotics within 90 days before the index period. The cases were also significantly more likely than the controls to have a history of renal failure, inflammatory bowel disease and cancer and to have had a previous diagnosis of MRSA infection (Table 2).

\section{Interpretation}

In this study of community-acquired CDAD, with cases defined on the basis of the patient having received a prescription for oral vancomycin therapy (whose only indication is the treatment of CDAD), we observed an increased risk of CDAD associated with current use of proton pump inhibitors. The es- 
timate of effect for $\mathrm{H}_{2}$-receptor antagonists was not found to be statistically significant. Comorbid illnesses determined to be associated with CDAD in previous studies ${ }^{1,4}$ (i.e., renal failure, inflammatory bowel disease, cancer and MRSA infection) remained significantly associated with $\mathrm{CDAD}$ in this study.

As in the previous study, ${ }^{1}$ antibiotics presented the highest risk of all the medications assessed; however, $45 \%$ of the case subjects had not received a prescription for antibiotics in the 90 days before vancomycin prescription. Most studies of $\mathrm{CDAD}$ have involved patients in acute care hospitals, where the prevalence of antibiotic exposure is high, ${ }^{14}$ which has likely contributed to the high rates of antibiotic exposure among CDAD patients in this setting. Also, because antibiotics frequently cause diarrhea and are believed to be in the causal pathway of CDAD, selection and ascertainment bias may be occurring. Patients receiving antibiotics are more likely than those not taking antibiotics to be tested and therefore receive a diagnosis of $\mathrm{CDAD}$, especially with recommendations that testing only be performed in patients with recent antibiotic exposure. ${ }^{15}$ In 3 studies performed in settings where the rate of antibiotic exposure in the source population was low (less than $15 \%$ ), rates of prior antibiotic exposure of $49 \%,{ }^{16}$ $50 \%{ }^{17}$ and $52 \%{ }^{18}$ among the CDAD cases were observed. At a recent workshop on clostridial disease, low rates of antibiotic exposure among patients with community-acquired CDAD were also reported. ${ }^{19,20}$ Therefore, patients with communityacquired CDAD may be less likely than those with hospitalacquired $\mathrm{CDAD}$ to have been previously exposed to antibiotics.

The use of 3 different case definitions for CDAD from a validated research database - laboratory diagnosis based on a positive toxin assay result $(n=833)$, physician diagnosis $(n=400)$ and receipt of a prescription for oral vancomycin therapy $(n=317)$ - yielded similar proportions of patients with prior proton pump inhibitor exposure $(24 \%$, $2 \mathrm{r} \%^{1}$ and $\left.19 \%\right)$. The proportion of patients who had previously been exposed to antibiotics was higher among cases defined on the basis of vancomycin treatment (55\%) than among those defined on the basis of a positive toxin assay result $(34 \%)$ or physician diagnosis $(38 \%) .{ }^{1}$ Because vancomycin is significantly more expensive than metronidazole and because metronidazole is suggested as the first-line agent for the treatment of $\mathrm{CDAD}$, it is possible that a case definition based on a prescription for oral vancomycin therapy may have resulted in certain biases. ${ }^{8}$ For example, if being given oral vancomycin therapy is a marker for more severe $\mathrm{CDAD}$, our estimates of drug effects may only be applicable to the risk of severe disease. It is possible that we included patients with relapses whose risk factors may have differed from those of patients with a first occurrence of CDAD. Also, if oral vancomycin therapy was prescribed as a second-line agent,

\begin{tabular}{|c|c|c|c|c|}
\hline Factor & $\begin{array}{c}\% \text { of cases } \dagger \\
n=317\end{array}$ & $\begin{array}{c}\% \text { of controlst } \\
n=3167\end{array}$ & Crude OR & $\begin{array}{c}\text { Adjusted } \\
\text { OR }(95 \% \mathrm{Cl}) \ddagger\end{array}$ \\
\hline Sex, male, no. (\%) & $116(36.6)$ & $1315(41.5)$ & $0.8 \quad(0.6-1.0)$ & $1.0 \quad(0.8-1.3)$ \\
\hline \multicolumn{5}{|l|}{$\begin{array}{l}\text { Comorbid conditions in the } 2 \mathrm{yr} \\
\text { before index dates }\end{array}$} \\
\hline \multicolumn{5}{|l|}{ Gastrointestinal } \\
\hline Inflammatory bowel disease & 5.7 & 0.2 & $36.0(13.3-97.0)$ & $46.1(14.5-146.7)$ \\
\hline Diverticular disease & 2.2 & 1.0 & $2.3(1.0-5.3)$ & $1.5 \quad(0.5-4.4)$ \\
\hline Peptic ulcer disease & 0.3 & 0.1 & $2.5 \quad(0.3-22.4)$ & $2.9 \quad(0.3-30.0)$ \\
\hline Gastroesophageal reflux disease & 4.1 & 2.2 & $2.0 \quad(1.1-3.6)$ & $0.9 \quad(0.4-1.9)$ \\
\hline \multicolumn{5}{|l|}{ Other } \\
\hline Renal failure & 5.3 & 0.7 & $8.7 \quad(4.4-17.2)$ & $6.2 \quad(2.7-13.9)$ \\
\hline Diabetes & 4.4 & 4.4 & $1.0 \quad(0.6-1.7)$ & $0.9 \quad(0.4-1.7)$ \\
\hline MRSA & 1.6 & 0.1 & $15.3 \quad(3.6-64.4)$ & $8.9 \quad(1.7-46.6)$ \\
\hline Cancer (solid tumour) & 1.6 & 0.4 & $4.3 \quad(1.5-12.4)$ & $4.9 \quad(1.5-16.5)$ \\
\hline Leukemia or lymphoma & 0.9 & 0.1 & $10.0 \quad(2.0-49.5)$ & 10.3 \\
\hline Pernicious anemia & 0.3 & 0.1 & $5.1 \quad(0.5-55.2)$ & $6.0(0.2-149.9)$ \\
\hline COPD & 6.6 & 3.1 & $2.3 \quad(1.4-3.8)$ & $1.1 \quad(0.6-1.9)$ \\
\hline \multicolumn{5}{|c|}{$\begin{array}{l}\text { Medications received in the } 90 \mathrm{~d} \\
\text { before index date, } \$ \text { no. (\%) of patients }\end{array}$} \\
\hline Proton pump inhibitor & $61(19.2)$ & $157 \quad(5.0)$ & $5.1 \quad(3.6-7.3)$ & $3.5 \quad(2.3-5.2)$ \\
\hline Antibiotic & $174(54.9)$ & $405(12.8)$ & $9.4 \quad(7.2-12.3)$ & $8.2(6.1-11.0)$ \\
\hline $\mathrm{H}_{2}$-receptor antagonist & $23(7.3)$ & 112 & $2.2(1.3-3.5)$ & $1.4 \quad(0.8-2.5)$ \\
\hline
\end{tabular}

Note: $\mathrm{OR}=$ odds ratio, $\mathrm{Cl}$ = confidence interval, MRSA = methicillin-resistant Staphylococcus aureus, COPD = chronic obstructive pulmonary disease. *Cases of CDAD are defined by receipt of prescription for oral vancomycin therapy. †Unless stated otherwise.

¥All variables in table were included in multivariate model to estimate adjusted ORs.

$\S$ The index date is the date of prescription for oral vancomycin therapy. 
these patients may have had diarrhea that was actually undiagnosed $\mathrm{CDAD}$ and in whom other antibiotic therapies (e.g., metronidazole or a quinolone) had failed. This could have increased our effect estimate of exposure to previous antibiotic agents (protopathic bias). This could also explain, in part, differences in the prevalence of antibiotic exposure between the cases seen in this study and those in a previous study, where the rate of prior antibiotic exposure was $37 \%{ }^{1}$

The UK health care system differs from the Canadian system in that general practitioners in the United Kingdom are responsible for overseeing the care of the patients in their practice, and budgetary adjustments are based on this premise. There may have been some unrecorded prescription information related to specialist visits, but it is unlikely to account for a high proportion of patients. Although the accuracy of the data is always a concern with database research, it has been reported that prescription information in the GPRD is extremely accurate ${ }^{11,13,21}$ and has been consistent throughout the period of study. Although the accuracy is shown to be of high quality for certain diagnoses, ${ }^{22}$ routine collection of such large amounts of data is inevitably subject to some constraints, since detailed diagnostic criteria cannot be laid down as in prospective studies. However, we believe that the consistency of the associations using the 3 different case definitions suggests that our definitions are valid.

In a community-based cohort, patients are less likely to be exposed to antibiotics and rarely receive multiple antibiotics concurrently. Under these conditions, it may be possible to gain a clearer estimate of the effect of nonantibiotic drugs on the risk of CDAD than in a hospital-based study, where antibiotic use is highly prevalent. The inability to demonstrate an association between acid suppressive agents ${ }^{23,24}$ and CDAD in some hospitalbased studies could have been due to residual confounding by indication. This is highlighted by the fact that underlying disease severity, ${ }^{25}$ a known risk factor for CDAD (as well as other nosocomial complications) may be highly correlated with both broad-spectrum and multiple antibiotic use. Recent hospitalbased studies ${ }^{3-5,26}$ and a large community study ${ }^{1}$ have described an increased risk of CDAD associated with proton pump inhibitor exposure. The results of this study, involving a different community cohort and a different case definition of CDAD, add additional weight to the evidence that proton pump inhibitor use is associated with an increased risk of CDAD.

\section{This article has been peer reviewed.}

From the Division of Clinical Epidemiology, Royal Victoria Hospital, McGill University Health Centre, and the Department of Epidemiology and Biostatistics, McGill University, Montréal, Que. (all authors)

\section{Competing interests: None declared.}

Contributors: All authors contributed to the conception and design of the article along with the acquisition, analysis and interpretation of data. All authors were involved in drafting and revising the article for important intellectual content and approved the final version to be published.

Acknowledgements: This study was funded by the Canadian Institutes of Health Research (CIHR) and the Canadian Foundation for Innovation. Sandra Dial is a Chercheur-Boursier Clinicien from the Fonds de la recherche en santé du Québec, and Samy Suissa is the recipient of a Distinguished Investigator Award from CIHR.

\section{REFERENCES}

I. Dial S, Delaney JAC, Barkun AN, et al. Use of gastric acid suppressive agents and the risk of community-acquired Clostridium difficile associated disease. JAMA 2005;294:2989-95.

2. Laheij R, Sturkenboom MC, Hassing R, et al. Risk of commuity-acquired pneumonia and use of gastric acid-supressive drugs. JAMA 2004;292:1955-60.

3. Cunningham R, Dale B, Undy B, et al. Proton pump inhibitors as a risk factor for Clostridium difficile diarrhoea. J Hosp Infect 2003;54:243-5.

4. Dial S, Alrasadi K, Manoukian C, et al. Risk of Clostridium difficile diarrhea among hospital inpatients prescribed proton pump inhibitors: cohort and casecontrol studies. CMAJ 2004;I7I(I):33-8.

5. Muto C, Pokrywka M, Shutt K, et al. A large outbreak of Clostridium difficile-associated disease with an unexpected proportion of deaths and colectomies at a teaching hospital following increased fluoroquinolone use. Infect Control Hosp Epidemiol 2005;26:273-80.

6. Pathology results and mailbox and mail administrator. In: In Practice Systems Training Services. Version 3 training guide. Available: www.inps.co.uk/vision trainingguide/IIv3tgma.pdf (accessed 2006 July 24).

7. NHS connecting for health clinical terminology service. Pathology Bounded Code List (PBCL) of read codes for pathology report messages (version I.oI2). Available: www .connectingforhealth.nhs.uk/pathology/tech_standards/docs/blior2.zip (accessed 2006 July 24).

8. Poutanen SM, Simor AE. Clostridium difficile-associated diarrhea in adults. CMAJ 2004; $17 \mathrm{I}(\mathrm{I}): 5 \mathrm{I}-8$

9. Bouza E, Munoz P, Alonso R. Clinical manifestations, treatment and control of infections caused by Clostridium difficile. Clin Microbiol Infect 2005;II(Suppl 4):57-64.

Io. Hollowell J. The General Practice Research Database: quality of morbidity data. Popul Trends 1997;87:36-40.

II. Walley T, Mantgani A. The UK general practice research database. Lancet I997; 350:1097-9.

I2. Jick H, Jick SS, Derby LE. Validation of information recorded on general practitioner based computerised data resource in the United Kingdom. BMJ I99I;302:766-8.

I3. Jick SS, Kaye JA, Vasilakis-Scaramozza C, et al. Validity of the general practice research database. Pharmacotherapy 2003;23:686-9.

I4. Dial S, Delaney JA, Barkun AN, et al. Gastric acid-suppressive agents and risk of Clostridium difficile-associated disease [letter]. JAMA 2006;295:2600-I.

I5. Fang FC, Gerding DN, Peterson LR. Diagnosis of Clostridium difficile colitis [letter]. Ann Intern Med I996;125:515.

I6. Simor AE, Yake SL, Tsimidis K. Infection due to Clostridium difficile among elderly residents of a long-term-care facility. Clin Infect Dis 1993;17:672-8.

I7. Wilcox $\mathrm{MH}$, Bendall R, Settle $\mathrm{CD}$, et al. Community Clostridium difficile infection [abstract no. L768]. In: Abstracts of the 4Ist Interscience Conference on Antimicrobial Agents and Chemotherapy. American Society for Microbiology; Chicago; 200I. p. 44I.

I8. Blot E, Escande MC, Besson D, et al. Outbreak of Clostridium difficile-related diarrhoea in an adult oncology unit: risk factors and microbiological characteristics. $J$ Hosp Infect 2003;53:187-92

I9. Engel J. Initiatives at the state level and performance characteristics of optimal surveillance systems. Slide presentation presented at Public Workshop on Emerging Clostridial Disease; 2006 May II; Atlanta. Available: www.fda.gov/cder/meeting /clostridia_disease.htm (accessed 2006 Aug 24).

20. McDonald LC. Surveillance for disease and sources of infection: initiatives at the federal level and international. Slide presentation presented at Public Workshop on Emerging Clostridial Disease; 2006 May II; Atlanta. Available: www.fda.gov /cder/meeting/clostridia_disease.htm (accessed 2006 Aug 24).

2I. Lawrenson R, Williams T, Farmer R. Clinical information for research; the use of general practice databases. J Public Health Med 1999;21:299-304.

22. Jick H, Jick SS, Gurewich V, et al. Risk of idiopathic cardiovascular death and nonfatal venous thromboembolism in women using oral contraceptives with differing progestagen components. Lancet I995;346:1589-93

23. Loo VG, Poirier L, Miller MA, et al. A predominantly clonal multi-institutional outbreak of Clostridium difficile-associated diarrhea with high morbidity and mortality. NEngI J Med 2005;353:2442-9.

24. Pepin J, Saheb N, Coulombe MA, et al. Emergence of fluoroquinolones as the predominant risk factor for Clostridium difficile-associated diarrhea: a cohort study during an epidemic in Quebec. Clin Infect Dis 2005;41:1254-6o.

25. Kyne L, Sougioultzis S, McFarland LV, et al. Underlying disease severity as a major risk factor for nosocomial Clostridium difficile diarrhea. Infect Control Hosp Epidemiol 2002;23:653-9.

26. Al Tureihi FI, Hassoun A, Wolf-Klein G, et al. Albumin, length of stay, and proton pump inhibitors: key factors in Clostridium difficile-associated disease in nursing home patients. J Am Med Dir Assoc 2005;6:105-8.

Correspondence to: Dr. Sandra Dial, Division of Clinical Epidemiology, Royal Victoria Hospital, 687 Pine Ave. W, Ross 4.29, Montréal QC H3A IAI; fax 514 843-I493; sandra.dial@mcgill.ca

Reprint requests to: Dr. Samy Suissa, Division of Clinical Epidemiology, Royal Victoria Hospital, 687 Pine Ave. W, Ross 4.29, Montréal QC H3A IAI; fax 5 I4 843-I493; samy.suissa@clinepi.mcgill.ca 